\title{
El hechizo del monstruo; una aproximación semiótica al cine de Weimar
}

\section{Artículo científico}

Adriana C. Cid

UCA / USAL ${ }^{1}$

Material original autorizado para su primera publicación en el Journal de Ciencias Sociales, Revista Académica de la Facultad de Ciencias Sociales de la Universidad de Palermo.

Recibido: 11-3-2016

Aceptado: 29-4-2016

Resumen: Partiendo de la base de la proliferación de la figura monstruosa en el cine de Weimar, el presente estudio propone un análisis semiótico de este aspecto, en films paradigmáticos de dicho período.

Se indagarán la ubicación del monstruo dentro de la trama de la película, el modo de configuración de la figura monstruosa y las estrategias discursivas fílmicas que intervienen en su plasmación.

Palabras Clave: cine de Weimar - monstruo(s) - imagen - semiótica de la imagen

Abstract: After establishing the proliferation of monstrous figures in the cinema of the Weimar period as a point of departure, the present article proposes a semiotic analysis of said topic throughout paradigmatic films of the era.

The main elements to be analyzed will be the monster's placement within the film's plot, the configuration of its figure, and the film discourse strategies relevant to its rendering on screen.

Keywords: Weimar period cinema-monster(s) - image - image semiotics

\footnotetext{
"Los monstruos no desaparecen con los mirabilia medievales, sino que regresan con el mundo moderno, aunque lo hacen bajo otra forma y con otra función."

Umberto Eco, Historia de la fealdad
}

\footnotetext{
${ }^{1}$ Licenciada en Letras por la UCA y Doctora en Filosofía, con especialidad en Filología Alemana, por la Universidad de Munich (Alemania). Docente e investigadora en las áreas de Literatura Alemana, Literatura Comparada, especialmente en Literatura y Cine, en la Universidad Católica Argentina y en la Universidad del Salvador. Presidente de la Asociación Argentina de Germanistas (AAG), miembro de la Asociación Latinoamericana de Germanistas (ALEG), de la Asociación Argentina de Literatura Comparada (AALC) y del Centro de Estudios de Narratología (CEN). Correo electrónico: adrianaccid@gmail.com
} 


\section{Algunas consideraciones preliminares}

A más tardar desde la publicación y enorme difusión del ensayo de Siegfried Kracauer De Caligari a Hitler (1947), se ha hecho la asociación del cine alemán de las primeras décadas del siglo pasado con el nazismo, concibiéndolo a modo de su prefiguración. Aún hoy, a pesar del carácter polémico y reduccionista de esta tesis, varios estudiosos siguen postulando que aquellos films ponían en imágenes lo que política y socialmente se estaba gestando. Expresado en términos junguianos, podría afirmarse que El gabinete del Doctor Caligari y otras películas de la época encarnarían -según esta línea interpretativa- la proyección de la sombra reprimida de una sociedad en profunda crisis.

Tampoco resulta novedosa la observación acerca de la reacción ambivalente del ser humano ante lo monstruoso, que oscilaría entre una natural repulsión y una cierta atracción morbosa. El dramaturgo y poeta alemán Friedrich Schiller por ejemplo, en uno de sus ensayos sobre la tragedia (1792) nos habla de la "fascinación de lo horrendo", como nos recuerda el mismo Umberto Eco. (Eco, 2011, p. 220)

Sin embargo, si bien no puede omitirse en un estudio sobre el cine de Weimar la mención a estas consideraciones, no nos detendremos en la polémica que de ellas pudiera resultar, ya que nos proponemos un abordaje de índole más concreta. Precisamente, partiendo de la evidencia de la proliferación de lo monstruoso en los films alemanes de este período, ${ }^{2}$ emprenderemos un intento de sistematización de las características, la estética y los modos de plasmación de tales figuras terroríficas en el lenguaje fílmico.

Para ello definiremos un corpus a partir de películas que puedan resultar paradigmáticas. Ellas son $E l$ estudiante de Praga (1913), de Paul Wegener, El Golem (1914, versión perdida; 1920, versión conservada), de Paul Wegener y Carl Boese, Homunculus (1916), de Otto Rippert, El gabinete del Dr. Caligari (1919), de Robert Wiene, Nosferatu; una sinfonía del horror (1922), de Friedrich Murnau, El gabinete de las figuras de cera (1924), de Paul Leni, Metrópolis (1926), de Fritz Lang y M, el vampiro de Düsseldorf (1931), del mismo realizador.

Se impone entonces como paso siguiente, definir al monstruo. Es un lugar común entre los especialistas la dificultad que ello encarna. Y aquí resulta pertinente volver al epígrafe. En este trabajo se

\footnotetext{
${ }^{2}$ No se puede desconocer que, junto a películas que se complacen en exhibir lo monstruoso valiéndose de una estética cercana al expresionismo o a lo fantástico, existe otra vertiente de cuño realista que los estudiosos -en las últimas décadas- intentan rescatar. Vicente Sánchez-Biosca por ejemplo, haciéndose eco de trabajos franceses sobre el tema, elige como título de uno de los apartados de su lúcido ensayo sobre el cine de Weimar, "La corriente ignorada: reivindicación del realismo". Sin embargo es necesario admitir que los films de mayor éxito y notoriedad son los primeros, es decir los que aquí nos ocupan.
} 
emplea el término "monstruo" en un sentido moderno y -cabe agregar- amplio: desde el sonámbulo Cesare en El gabinete del Dr. Caligari, pasando por el vampiro en Nosferatu, y el Golem de la película homónima, hasta la autómata-robot de Metrópolis, encarnan modalidades de lo monstruoso. En su Historia del cine, por ejemplo, el estudioso Román Gubern subtitula el capítulo dedicado a estas décadas del cine alemán: "De los monstruos al realismo". Coincide también en tal amplitud de criterio el especialista italiano Massimo Izzi, quien en su Diccionario ilustrado de los monstruos, no solo dedica entradas a una gran variedad de demonios orientales y occidentales por ejemplo, sino que también da cabida a la galería de criaturas monstruosas que desfilan por estas películas. Izzi postula que cada tradición y cada cultura crean sus propios monstruos, mediante un mecanismo de la mente humana, de la imaginación, que resulta digno de estudio (Izzi, 1996, pp. 5-6). A la vez considera que los monstruos pueden pertenecer tanto al orden mítico como al biológico y que se caracterizan por presentar aspectos desviados, híbridos, anómalos y alguna deformidad o malformación (Izzi, 1996, p. 5). Umberto Eco, por su parte, asocia a los monstruos con "una estética de la desmesura" (Eco, 2011, p. 111).

Aclarado el concepto de monstruo que se aplicará en este artículo, falta aún una breve advertencia sobre el alcance de la expresión "cine de Weimar". Si bien históricamente la República de Weimar se inicia en 1918, con el fin de la Primera Guerra Mundial, y acaba en 1933, con la instauración del tristemente célebre Tercer Reich, suele tomarse tanto en la Germanística como en la Historia del Arte, del Teatro, del Cine, de la Cultura y aun en la Sociología, con una cierta laxitud en el arco temporal. Voces tan autorizadas y diversas entre sí, como las de Lotte Eisner, Siegfried Kracauer, Román Gubern, Vicente Sánchez-Biosca, Peter Gay entre otros, optan por asignar un sentido amplio a la expresión. Acaso las palabras del historiador berlinés Peter Gay puedan servir a modo de síntesis y condensación de esta postura:

No hay duda: el estilo de Weimar nació antes de la República de Weimar. Lo que hizo la guerra fue darle proyección política, un tono estridente. [...] El espíritu de Weimar nació antes que la República de Weimar, al igual que su bestia negra. (Gay, 2011, p. 25; 104) ${ }^{3}$

Prueba de esto son también las películas seleccionadas. Algunas de ellas datan de antes de 1918, en tanto que las últimas son bastante anteriores a 1933. Lotte Eisner, Román Gubern, Vicente Sánchez-Biosca, aun cuando en sus análisis distinguen antecedentes y precursores, extienden en la práctica en esos mismos estudios, las fronteras del concepto "cine de Weimar".

\footnotetext{
${ }^{3}$ Aunque pueda resultar superfluo, preferimos explicitar que con “la bestia negra”, Peter Gay se refiere a Adolf Hitler.
} 
En cuanto al final de este período histórico-político, los investigadores coinciden en que se agota antes, el impulso humanista y creativo de Weimar.

En lo que al cine se refiere, existe una explicación para el prematuro eclipse. En 1927, la UFA (Universum Film AG) había entrado ya en bancarrota y había sido comprada por Alfred Hugenberg, miembro del partido nacional-socialista (NSDAP), quien la tomó con la intención de que sirviera al aparato de propaganda política. Aquí empieza el declinar del cine de Weimar, conocido aún hoy como la época de oro del cine alemán. ${ }^{4}$ Acaso las dos últimas grandes películas fueron Metrópolis, de Lang, y Fausto, de Murnau, ambas rodadas simultáneamente en 1926, en sets de filmación colindantes.

Por tal razón, algunos historiadores se refieren a esos años finales bastante anteriores a 1933, como "epílogo de Weimar".

Presentadas ya estas advertencias y aclaraciones preliminares, nuestra propuesta consiste entonces en explorar tres instancias en las que -consideramos- queda de manifiesto la modalidad de representación de lo monstruoso dentro de este corpus de películas. La primera podría resumirse en la pregunta por el lugar que se asigna al monstruo dentro de la trama del film; la segunda coincidiría con el interrogante por su configuración estética, y en la última, se intentaría esclarecer cuáles son las estrategias discursivas fílmicas que intervienen en la composición de la criatura monstruosa.

\section{El monstruo dentro de la fábula}

Partiendo desde lo más general, podría plantearse la pregunta acerca del lugar que ocupa el monstruo dentro de la fábula y de las conexiones que con él se establecen.

\footnotetext{
${ }^{4}$ Aunque ello exceda el objeto del presente estudio, parece importante exponer sucintamente las peculiaridades de este cine y el contexto en el que surge. Al finalizar la Primera Guerra Mundial, Alemania había quedado vencida, desestabilizada, devastada, pero se mantenía vital el debate intelectual y artístico. En el ámbito del cine, la Alemania de los años '20 se enfrentaba a dos cosmovisiones divergentes que pretendían imponerse en el mercado: el capitalismo norteamericano con la poderosa industria de Hollywood detrás, que se extendía con claras intenciones hegemónicas tanto en EE.UU. como en Europa, y el comunismo soviético, que también se valía del cine a través de la distribuidora Prometeo y del partido comunista alemán, para expandir su influencia al resto de Europa. El cine alemán entonces, intentó posicionarse en un mercado agresivo y se propuso redefinirse y adquirir así perfil propio. Describe muy bien esta encrucijada la historiadora de cine Pilar Pedraza: "Sobre todo se trataba de crear un producto cultural, moderno y de masas, de prestigio, utilizando el cine alemán como un instrumento capaz de competir con las obras monumentales soviéticas [...] y con las superproducciones de Hollywood. [...] Para eso se contaba con la gran fábrica de sueños alemana, la UFA, dirigida en esa época por Erich Pommer. [...] La UFA produjo mucho cine deleznable, pero también una cantidad inusitada de obras maestras, durante la década turbulenta y amarga que siguió al Tratado de Versailles. [...] Formó además, equipos de técnicos sólidamente preparados, muchos de los cuales también se exiliaron. Su manera de trabajar disciplinada, basada en el equipo de director, era industrial como la de Hollywood, pero con un carácter más marcadamente artesanal en la producción, predominando el director con sus criterios y su facultad de supervisión, sobre la organización en cadena [...] del cine de Hollywood." (Pedraza, 2000, pp. 29-30)
} 
En algunos casos, observamos que el monstruo está ya presente en el paratexto, desde el título mismo, como en Homunculus, El Golem, Nosferatu, o M. el vampiro de Düsseldorf. Al ubicarse en los umbrales mismos del texto fílmico, la criatura monstruosa contribuye a desplegar en el espectador un horizonte de expectativas que avanza hacia lo siniestro.

Si nos concentramos en su posición jerárquica, interesa destacar que la figura monstruosa, si bien puede asumir un rol protagónico, como en los dos films sobre vampiros ya mencionados, suele presentarse con frecuencia, subordinada a otro personaje, sea como creación de este o sometida a su poder.

Probablemente el ejemplo más célebre lo constituya El gabinete del Dr. Caligari. En esta película, hito en la historia del cine, el sonámbulo Cesare, extraña criatura con rasgos de autómata, no solo es convertido por su amo, el excéntrico Dr. Caligari, en atracción de feria, sino que, dominado por él, se lanza por las noches a cometer horrendos crímenes.

Una díada similar se registra en El Golem, donde la creación de arcilla surgida de la cábala acaba rebelándose contra el rabino que le insufló la vida y contra toda la comunidad del ghetto judío. Finalmente, será una pequeña niña rubia -inquietante prefiguración del “ideal ario" que expandirá algunos años más tarde el Tercer Reich- quien logre calmar y someter al monstruo.

En Homunculus, se verifica una tensión criatura-creador bastante semejante. El humanoide Homunculus, creado artificialmente por el Dr. Hansen, al conocer su origen y su verdadera naturaleza, reacciona violentamente contra el científico y contra su entorno.

En otro film emblemático como Metrópolis, se articula una vez más este tipo de dupla entre el inventor Rothwang y el robot-autómata que derivará en la falsa Marie, llamada a confundir y exaltar a la multitud.

A la luz de estos ejemplos, cabría postular que mediante tales binomios, se introduce en el cine de Weimar el motivo del doble en tanto sombra negada y temida, que se presenta como modalidad de lo ominoso. 
Por otra parte, tras el visionado de estas películas, surge, provocadora, la pregunta acerca de quién es en verdad el monstruo. ¿Homunculus, que descubre en su interior un mundo de sentimientos, se identifica por su aspecto con los seres humanos, pero se sabe sin alma e incapaz de amar? ¿O el científico que lo creó en un laboratorio alucinante pero, una vez que comprueba que la criatura se ha emancipado, intenta destruirlo y crea para ello un segundo Homunculus? Pasando a Caligari, ¿resulta más terrorífico en sus reacciones y actitudes Cesare o el Doctor? Puntualiza al respecto Lotte Eisner:

Notemos que los personajes de Caligari y de Cesare están totalmente en consonancia con la concepción expresionista: el sonámbulo, apartado de su ambiente cotidiano y privado de cualquier individualidad, criatura abstracta, mata sin motivo ni lógica. En cambio su amo, el misterioso doctor Caligari, que no tiene ni sombra de escrúpulos humanos, actúa con una insensibilidad loca, con ese desafío a la moral corriente que los expresionistas exaltan. (Eisner, 1996, p. 32)

Toda esta serie de duplas suscita interrogantes similares, y en una instancia ulterior, encubre un cuestionamiento acerca de la función y los limites de la ciencia en los inicios del siglo XX.

Otro elemento para nada desdeñable vinculado al monstruo en la pantalla de Weimar es la utilización de las multitudes. Si bien el teatro expresionista, en especial en las puestas de Max Reinhardt y Erwin Piscator, apelaba a este despliegue de actores, coros y figurantes en escena, no parecía tarea sencilla dinamizar de este modo el relato fílmico. Sin embargo, Wegener y Boese lo intentan algo tímidamente en EI Golem, en tanto que Rippert en su Homunculus y Lang en Metrópolis, lo resuelven con singular maestría. Una vez más, cedemos la voz a Lotte Eisner, quien se refiere al tratamiento de las multitudes en estos films:

La influencia de Homunculus en Metrópolis se revela sobre todo en algunos movimientos de masa que recuerdan de manera muy precisa a la multitud excitada alzada contra Homunculus y que luego se despliega en triángulo lanzándose hacia la escalera. (Eisner, 1996, p. 152)

Y prosiguiendo con el análisis de las masas humanas, concluye Eisner con contundencia: "Los habitantes de la ciudad subterránea [en Metrópolis] son mucho más autómatas que el robot creado por el inventor Rothwang. [...] La estilización expresionista transforma lo humano en elemento mecánico." (Eisner, 1996, p. 154).

Si bien la crítica al hombre masa constituye uno de los tópicos claves del expresionismo, dentro de este corpus la problemática se complejiza y adquiere distintos niveles de significación. La prefiguración de una multitud acrítica, obnubilada por el nazismo es sin duda uno de ellos. 
La figura del monstruo se entrelaza asimismo con diversos motivos que van urdiendo un mundo hoffmanniano: el doble, el espejo, la sombra, el vampirismo, la locura, las alucinaciones, el sonambulismo, las pesadillas. Muchos de estos motivos configuran verdaderos image systems ${ }^{5}$ que trasladan la atmósfera inquietante del film, al espectador.

A lo largo de este trabajo iremos espigando estas problemáticas, pero de momento, esbozaremos algunas cuestiones vinculadas al motivo del espejo, crucial en la mayor parte de estos films. Para ello seguiremos de cerca el fascinante estudio Historia del espejo, de la catedrática francesa Sabine MelchiorBonnet.

La autora parte de la afirmación de que se trata de un objeto ambiguo al que se le adjudican poderes mágicos e inquietantes (Melchior-Bonnet, 2014, p. 16; 33). Además, como ofreciendo un andamiaje para la comprensión más profunda de diferentes textos literarios y fílmicos, uno de los cuales bien podría ser El estudiante de Praga, asocia al espejo con la locura y comenta: "Después de haber simbolizado el espanto producido por los poderes sobrenaturales, reflejaba la imagen de los demonios interiores y de una posibilidad amenazadora que trastornaba la identidad." (Melchior-Bonnet, 2014, p. 288).

La película que necesariamente evocamos es la de Paul Wegener, donde el espejo adquiere carácter protagónico. El joven Balduin, estudiante en Praga, por afán de ascenso económico-social, firma un pacto con el diablo. Este, camuflado bajo el grotesco personaje Scapinelli, que aquí -junto con el reflejo de Balduin- funciona como la criatura monstruosa (¿o como su amo?) con todos los rasgos de tal, toma a cambio de lo que le otorgará, el reflejo del estudiante. (Obsérvese de paso, que aquí se sustituye el motivo popular de la venta del alma, por la del reflejo.)

Wegener engarza en la trama del film tres sugerentes sobreencuadres de Balduin contra espejos, que trazan un dramático crescendo hasta culminar en el desenlace final. El primero corresponde a la escena del pacto, en el momento inmediatamente posterior a la firma. El estudiante y Scapinelli aparecen reflejados en el mismo espejo, las cabezas juntas, una al lado de la otra. Si -como afirma André Gaudreaultla esencia del lenguaje fílmico es la mostración, este plano de cámara fija da cuenta, de manera indubitable, de la unidad siniestra que ambos personajes acaban de sellar. Sin embargo, repentinamente el reflejo del

\footnotetext{
${ }^{5}$ Tomamos el concepto de image system del investigador italiano Armando Fumagalli. Se trata de una microestrategia narrativa cinematográfica que consiste en la presentación de objetos en diferentes momentos y contextos del relato fílmico, a los que se asigna carácter simbólico (Fumagalli, 2004, p. 98).
} 
joven desaparece del espejo, se desplaza como un autómata, se emancipa y se convierte en su doble sin más. Balduin iniciará entonces una desesperada búsqueda de su reflejo, pero solo encontrará frente a sí espejos vacíos.

Los otros dos sobreencuadres se articulan muy cercanos el uno del otro, ya promediando el film. Contra un ventanal, cuyas ligeras cortinas se agitan suavemente con el viento, se proyecta la imagen del doble emancipado de Balduin. El relato fílmico sugiere que nuestra mirada de espectadores coincide con la del estudiante, quien -llevado por el espanto y la desesperación- toma un revólver y dispara contra el reflejo. Se inserta entonces el tercer sobreencuadre -singular, desbalanceado- del joven tendido en el piso, agonizante, contra el espejo roto, que, por fin, le devuelve su reflejo.

¿Alucinaciones?, ¿esquizofrenia?, ¿locura?, ¿artes demoníacas? Todo ello junto, en un relato que se nutre del Romanticismo alemán más negro.

Como cierre de estas consideraciones sobre el espejo, resulta sumamente iluminadora la observación de Melchior-Bonnet: “Un estudio sistemático de las imágenes del espejo en el arte del siglo XX mostraría la recurrencia del espejo vacío y del espejo roto." (Melchior-Bonnet, 2014, p. 393).

Otro núcleo temático que se teje alrededor del monstruo en estas películas es la historia de amor trágico, tensada hasta lo bizarro. Sirvan a modo de ejemplo las figuras de la hija del científico que se enamora de Homunculus, aunque sabe de su imposibilidad de amar, o de Ellen, la "mujer-ángel", que decide ofrendarse en el film Nosferatu, y así acabar con el vampiro y con la peste. Vicente Sánchez-Biosca, que confiere a su estudio sobre el cine de Weimar una impronta freudiano-lacaniana, se refiere a este tipo de mujer como "la histérica" (Sánchez-Biosca, 1985, p. 68). Resulta evidente que el motivo del amor trágico se ensambla en estos films con dos tópicos románticos que recoge y reelabora el Expresionismo: el de la bella y la bestia, y el de la mujer-ángel y su contracara, la mujer-demonio, tan magníficamente traducidas en la pantalla por Brigitte Helm, la actriz que encarna a la Marie “ángel” y la Marie "demonio" en Metrópolis.

Sin duda muchos otros motivos y topoi se entrelazan en la composición de estas películas, pero aquí, dada la extensión propia de un artículo, hemos intentado ofrecer una selección de algunos de los más representativos. 


\section{Configuración estética del monstruo}

Resulta casi una obviedad que si decidimos indagar la representación del monstruo en el cine de Weimar, nos planteemos la pregunta por su configuración estética o -expresado en otros términos- por su aspecto y características más externas.

Una de las notas sobresalientes es sin duda la altura desmesurada. Recordemos que Umberto Eco vincula lo monstruoso con la "estética de la desmesura" (Eco, 2011, p. 111). En cantidad de planos dentro de este corpus, se busca exponer la -en muchos casos- notable diferencia de tamaño de la figura monstruosa en relación con el resto de los personajes. Para ello se acude a encuadres de figura entera en los que el monstruo se halla en compañía de uno o más personajes. Particularmente el Golem, el sonámbulo Cesare y la autómata-robot de Metrópolis en la escena del laboratorio destacan en esta serie de películas.

Los vampiros por su parte, que no están representados con una altura tan desmedida, acrecientan sin embargo sus dimensiones en la proyección de su sombra.

Asimismo este rasgo, que en algunos casos como el del Golem, se exacerba hasta el gigantismo, se plasma también en aquellas tomas en las que se incluye el entorno espacial. El Golem por ejemplo, en planos trabajados, de manera muy lograda para la época, con la técnica de sobreimpresión de fotogramas, avanza por las calles del pueblo, mientras las casas se ven diminutas a su lado (ver apéndice, fotograma 1).

Vinculada con las medidas, se evidencia también otra característica de la figura monstruosa como es la desproporción en las partes mismas de su cuerpo. De manera recurrente, el cine de Weimar configura al monstruo enfatizando alguna falta de relación entre rostro, torso y extremidades. Esta nota es particularmente ostensible en el Golem, cuya caja torácica y cabeza se hallan sobredimensionadas en relación con el resto del cuerpo (ver apéndice, fotograma 2). Sin embargo también se registra en algunas otras criaturas monstruosas que integran esta galería. Cesare por ejemplo es una figura longilínea, cuyo rostro resulta relativamente pequeño (ver apéndice, fotograma 3). La desproporción en Nosferatu se halla en las manos, largas, delgadas y configuradas como garras, aunque en especial en algunas tomas, se tiene también la impresión de estar ante un ser con una cabeza algo pequeña.

Un elemento adicional que contribuye a la configuración estética de la figura monstruosa es la deformidad grotesca. Permítasenos aquí de paso, recordar la teoría de Izzi, quien asigna al monstruo alguna 
deformidad o malformación (Izzi, 1996, p. 5). Esta deformidad grotesca se encuentra particularmente subrayada en el Golem, Homunculus, Cesare y Nosferatu. La Marie de Metrópolis podría ser considerada una excepción en este sentido; sin embargo, en las escenas con la multitud, también ella exhibe la distorsión del grotesco en su gestualidad exacerbada, y su rostro se desfigura en una mueca.

Wolfgang Kayser, que exploró el grotesco en la literatura y la pintura, asocia esta estética -en alguna de sus vertientes- con el efecto de lo ominoso e incluso afirma: "la configuración de lo grotesco constituye la tentativa de proscribir y conjurar lo demoníaco en el mundo". ${ }^{6}$ (Kayser, 1964, p. 228). Es indudable que tal modalidad de estética grotesca se aplica a nuestro corpus. Asimismo el teórico alemán distingue dos operaciones de transformación que intervienen en la representación de lo grotesco; ellas son la demonización y la animalización (Kayser, 1964, pp. 127-128). Si pasamos revista al corpus, se constata rápidamente que ambas formas, tanto la estilización demoníaca como la animalesca, conviven en las criaturas monstruosas de estos films. El monstruo -y en ocasiones también su amo o creador-presentan ojos con mirada fija o extraviada, ojeras acentuadas que contrastan con la palidez extrema del rostro, cejas excesivamente tupidas, orejas puntiagudas, cabellera despeinada y casi enmarañada o bien calvicie extrema -como en el caso de Nosferatu-, manos como garras, deformidad del cuerpo como alguna joroba por ejemplo, rasgos todos ellos que evocan ya lo diabólico, ya lo animal (ver apéndice, fotograma 4). En particular el rostro, estilizado así en grado sumo y sujeto a tal tratamiento grotesco, logra el efecto netamente expresionista- de la máscara.

Por último, si la definición más elemental que se puede dar del cine es la de "imágenes en movimiento", no debería soslayarse en el análisis de la figura monstruosa, el tratamiento kinético. Asimismo, Kayser argumenta que lo grotesco no solo se plasma en el aspecto o apariencia del personaje en cuestión, sino que también afecta a las actitudes, los movimientos y la gestualidad (Kayser, 1964, p. 128). Efectivamente, los movimientos de estas criaturas monstruosas destacan por lo anómalos. A su vez, como lúcidamente advierte Lotte Eisner, en ocasiones producen un efecto exasperante en el espectador (Eisner, 1996, p. 78). Analizando el corpus, se identifica todo un abanico de variantes, que a veces coinciden en la misma figura o en el mismo film: movimientos convulsos, como suelen darse en Caligari; rígidos, atribuidos en especial al Golem, figura de piedra o arcilla, pero también a Nosferatu; mecánicos, como en el caso de la autómata o del reflejo de Balduin; eufóricos y descontrolados, en las escenas en las que la autómata arenga

\footnotetext{
${ }^{6}$ Kayser también reconoce la modalidad del grotesco satírico propio de la comedia, que -utilizado como recurso al servicio del humor- no presentaría rasgos de ominosidad (Kayser, 1964, p. 229).
} 
a la multitud. Por otra parte, en algunos pasajes el monstruo se desplaza con excesiva lentitud, en tanto que a otros, se les imprime un vértigo inusual.

En el capítulo que dedica a Nosferatu, film al que califica de "pesadilla viviente", Lotte Eisner presenta un esclarecedor análisis de las elecciones kinéticas de Murnau, que, parcialmente, quisiéramos reproducir para clausurar este apartado:

Murnau crea una atmósfera de horror por los movimientos de los actores hacia la cámara: la horrible forma del vampiro avanza, con una lentitud exasperante, de la profundidad extrema de un plano hacia otro, en donde de repente se hace gigantesca. Murnau ha aprovechado todo el poder visual que emana de una montaña, y dirige con una virtuosidad verdaderamente genial esa serie de planos, que dosifican el avance del vampiro mostrando durante algunos segundos el efecto que provoca su presencia en el aterrorizado joven. [...] Murnau también sabe hacer valer el poder de un movimiento transversal extendiéndolo sobre toda la superficie de la pantalla: es el sombrío barco fantasma bogando a toda vela en un mar encrespado y llegando a puerto, lleno de amenazas; o la silueta enorme del vampiro, filmada en picado, que atraviesa lentamente el velero para alcanzar a su presa. Aquí el ángulo de la cámara le confiere, además de sus proporciones gigantescas, una especie de oblicuidad que lo proyecta fuera de la pantalla y hace de él una amenaza tangible, en tres dimensiones (Eisner, 1996, p. 78).

\section{El monstruo desde el ojo-cámara}

Quedaría por último indagar las estrategias discursivas fílmicas que intervienen en la representación del monstruo en el corpus aquí propuesto.

Aun en un cine limitado al blanco y negro por las condiciones técnicas propias de la época, el tratamiento cromático merece especial consideración, tanto más teniendo en cuenta que en estos films se apela a un cromatismo apartado de lo neutro.

A la criatura monstruosa -como Cesare, Nosferatu, el vampiro de Düsseldorf- suele asignársele el color negro o, en su defecto, tonalidades oscuras de grises, como en el caso del Golem. El negro se halla tanto en la indumentaria como en el rostro. Siguiendo la estética del maquillaje teatral expresionista, ${ }^{7}$ el contorno de ojos aparece fuertemente delineado, y los párpados, sombreados, hasta semejar una máscara, según ya se ha hecho mención.

\footnotetext{
${ }^{7}$ El teatro expresionista -como se recordará- fue antecedente ineludible del cine de Weimar.
} 
Por otra parte, en todos estos films existe un relegamiento del mundo diurno, y ello no es casual, ya que el "espacio" de estas criaturas es la noche. Al amparo de las sombras, se deslizan subrepticiamente, atacan, sorprenden y aterrorizan a sus víctimas, cometen sus crímenes.

Pero no solo la oscuridad de la noche enfatiza la negrura del monstruo, sino también otro juego cromático como es el fuerte contraste que se establece con la figura de la víctima y su ambiente. Las mujeres que son perseguidas y acosadas por estas criaturas deformes aparecen envueltas en vaporosas túnicas blancas. Sus cuartos se ambientan según un patrón similar: ropa de cama inmaculadamente blanca, que enmarca, de modo redundante, la figura femenina, y ventanas o ventanales que dan a un balcón con las hojas abiertas o semiabiertas, cubiertos con cortinados de voile blanco que ondean suavemente al viento, que asume a su vez un "papel dramático" ${ }^{8}$ como presagiando la llegada del monstruo.

Resulta interesante advertir una variante de este contrapunto cromático en la película de Paul Wegener y Carl Boese. Allí la blancura de los vestidos no se observa en los personajes atacados por el Golem, sino en la diminuta niña que se acerca a él al promediar el film y le tiende la mano, desarticulando así toda reacción violenta de su parte (ver apéndice, fotograma 5).

Íntimamente vinculada con lo cromático, se halla la dimensión lumínica. Ya se ha puntualizado que en estas películas existe una dominancia de lo nocturnal. Cabría agregar ahora que también se percibe en ellas una predilección por los juegos de luces y sombras y por el claroscuro, -estética, por otra parte, muy cara al expresionismo alemán.

La sombra es un elemento omnipresente y por momentos adquiere casi la categoría de personaje. En varias escenas de distintos films asume la función de doble ominoso del monstruo o incluso lo reemplaza, como sucede en Nosferatu, en donde como espectadores, vemos avanzar, proyectada en la pared que linda con una escalera, la sombra acechante del vampiro (ver apéndice, fotograma 6). Si el doble -según afirma Freud- encarna una de las modalidades de lo siniestro, la sombra, que anticipa y anuncia la llegada del monstruo, subraya su ominosidad.

\footnotetext{
${ }^{8}$ Tomamos de Lotte Eisner el concepto de "papel dramático" del viento (Eisner, 1996, p. 112), si bien ella lo aplica al análisis del film Los Nibelungos, de Fritz Lang.
} 
A ello se añade el hecho de que la sombra proyectada en estas secuencias aumenta las dimensiones de la figura original y distorsiona sus rasgos, ya de por sí deformes -como las garras o la joroba-, exagerándolos.

El monstruo así duplicado en su proyección o la sombra quasi emancipada agigantan la imagen malformada y se vuelven altamente perturbadores.

Otra duplicación inquietante de la criatura monstruosa se logra con sobreencuadres contra espejos. Nos parece oportuno recordar aquí uno de los efectos -además de los enumerados en un apartado anterior- que Melchior-Bonnet atribuye al espejo: "Factor de sorpresa e instrumento de doble juego, el cristal desestabiliza la mirada." (Melchior-Bonnet, 2014, p. 342). Sin duda este juego desestabilizador de la mirada propuesto desde la pantalla cinematográfica incide directamente en el espectador. Detengámonos ahora en la estrategia del sobreencuadre -tan hábilmente utilizada más tarde por directores como Orson Welles, por ejemplo-. Este recurso permite no solo enmarcar la figura, sino también realzarla, y combinado generalmente con el plano de cámara fija- congela el flujo temporal, al servicio del suspenso. En especial Nosferatu, de Murnau, y la temprana película El estudiante de Praga, de Wegener, -a la que ya parcialmente, nos hemos referido- introducen este procedimiento y-como se recordará- el motivo del espejo, de manera sumamente productiva en escenas climáticas.

Al sobreencuadre contra espejos se suma el sobreencuadre contra aberturas. En estos films se percibe una preferencia por las ventanas más que por las puertas, ya que aquellas posibilitan vigilar a la víctima, a la vez que un eventual ingreso subrepticio a su habitación. Al igual que en el caso de los sobreencuadres contra espejos, se apela también aquí a la cámara fija, que insiste en la figura del monstruo inmóvil y al acecho de la víctima, potenciando así lo terrorífico. Una vez más es Murnau con su Nosferatu, quien compone uno de los más logrados sobreencuadres dentro de este corpus. Presenta una suerte de ventana sin vidrios, dividida en nueve cuadrículas, ordenadas en grupos horizontales de tres. Mientras las varillas que delimitan las cuadrículas poseen un tono gris y una leve iluminación, el resto se halla dominado por el negro. Contra tanta oscuridad, la figura del vampiro, con sus consabidas ropas negras, aparece -como es de suponer- muy poco definida. De este modo, Murnau -no en vano llamado "el gran luminista" - logra concentrar toda la atención en el rostro y las garras del monstruo, enmarcado exactamente en el centro de la ventana y bañado en una hiriente luz blanca (ver apéndice, fotograma 7). 
Sin embargo, dado que una película se concibe como montaje y devenir temporal, es necesario analizar el recurso del sobreencuadre en el contexto de su composición, y en este sentido, resulta imprescindible mencionar el juego que se introduce entre un plano y su contraplano. Si a Cesare, al Golem, a la autómata o a los vampiros, se los enmarca en un plano con sobreencuadre, a sus potenciales víctimas se les concede el siguiente contraplano y se las presenta inocentes, vulnerables y, en muchos casos, tendidas sobre sus camas y dormidas, es decir totalmente indefensas. La figura del monstruo contra la ventana crece en ominosidad porque -en tanto espectadores- sabemos que Nosferatu está observando, justamente enfrente, la ventana del cuarto de su víctima. Asumimos entonces la ocularización del vampiro, pero, lejos de identificarnos con él y con sus intenciones, se nos plantea como espectadores, el trayecto del espanto, ${ }^{9}$ al sentir empatía por la joven dormida.

En tales entramados de planos y contraplanos dedicados a víctima y victimario respectivamente, cobra singular peso el fueracampo, elemento al que los especialistas en lenguaje fílmico asignan especial significación. Si en el campo visual se ubica el personaje monstruoso, no desconocemos que fueracampo (en la composición y para nosotros como espectadores), pero al alcance del agresor, se halla su víctima. De manera similar, resulta estremecedor el encuadre de una joven ignorante de la amenaza que se cierne sobre ella, trabajado con iluminación subrayada, porque se nos retacea -apenas momentáneamente- la visión del monstruo, al acecho, desde un perturbador fueracampo.

En estrecha relación con las estrategias discursivas aquí abordadas, se encuentra el tratamiento temporal de estas secuencias, caracterizadas predominantemente por un tempo lento. Tales juegos de planos y contraplanos, en los que se incluyen aquí y allá sobreencuadres, suelen componerse desde la cámara fija, que prolonga las escenas y -como ya se ha señalado en un apartado anterior-interrumpe el fluir temporal. Asimismo se recurre a primeros planos del monstruo y de la víctima y a planos detalle de garras y manos, que producen el mismo efecto de tiempo suspendido.

Todos estos componentes, hábilmente articulados e integrados, contribuyen al suspenso y enfatizan la atmósfera siniestra del film. En este punto, no nos parece ocioso recuperar un concepto de Giuliano Torrengo, filósofo italiano estudioso del tiempo en la ciencia ficción. En nuestra opinión, algunas de sus categorías podrían resultar válidas para aplicar a este análisis. Entre otros aspectos, Torrengo reconoce en el tiempo, dos determinaciones bien diferenciadas, la atensional y la tensional. (Torrengo, 2011, p. 6) La

\footnotetext{
${ }^{9}$ Tomamos de Francesco Casetti el concepto de trayecto del espectador. Según el especialista italiano, todo film plantea a su espectador un determinado "trayecto de lectura" (Casetti, 1996, p. 14).
} 
primera es neutra y de índole puramente cronológica. Consideremos como ejemplo la siguiente afirmación: "El ciclo sobre Cine de Weimar se iniciará el mes próximo". Este dato en sí mismo no posee carga emocional alguna ni ejerce ninguna tensión hacia el futuro, aunque el ciclo de cine efectivamente se vaya a desarrollar en un tiempo por venir. La determinación tensional por el contrario, imprime subjetividad al tiempo y es la que domina en las películas de espionaje o de terror por ejemplo. En el caso de nuestro corpus, se pone de manifiesto una paradoja que encuentra su correlación en el espectador. Por un lado, el relato adquiere la morosidad propia del tempo lento, pero por otro, ese flujo temporal congelado por sobreencuadres y primeros planos del monstruo o planos de su sombra y por primeros planos de la víctima provoca en el espectador una fuerte tensión por lo que habrá de suceder.

Un párrafo aparte merece la recurrencia de los primeros planos, tanto del monstruo, como del personaje que supuestamente podría dominarlo (el Dr. Caligari en el caso de Cesare, el rabino en relación con el Golem, el Dr. Hansen con Homunculus, y Rothwang con la autómata de Metrópolis), como de sus víctimas. En su estudio sobre El rostro en el cine, advierte el especialista francés Jacques Aumont que las tomas de primeros planos pueden generar efectos diversos, aunque los más frecuentes son dos: la rostrificación y la desrostrificación (Aumont, 1998, pp. 88-89). Mediante el primer plano de rostrificación, la expresión del personaje se vuelve transparente y el espectador puede acceder así a sus sentimientos más íntimos. En el efecto de desrostrificación por su parte, el rostro semeja una máscara, se distorsiona y pierde sus rasgos humanos. Aun el más superficial visionado de estos films permite constatar que en ellos se alternan ambos efectos de los primeros planos en una tensión tal que -en ocasiones- incluso se solapan. Así por ejemplo los rostros de las víctimas trasuntan ostensiblemente el terror que las invade ante la presencia del monstruo en una clara rostrificación, pero a la vez, adhiriendo de manera innegable a una línea estética expresionista, los ojos y la boca desmesuradamente abiertos y la gestualidad exagerada, remedan una máscara y conducen a la desrostrificación.

En lo que al monstruo se refiere, prima -como es lógico- el efecto de desrostrificación, que busca deshumanizarlo aún más.

Otra constante de este corpus del cine de Weimar es la combinación del encuadre frontal neutro con encuadres descentrados y angulación de cámara ya hacia abajo, en picado, ya hacia arriba, en contrapicado, que generan un efecto desestabilizador sobre el espectador. 
Las angulaciones en picado y contrapicado se presentan en ocasiones, de manera complementaria en planos y contraplanos sucesivos. Al monstruo se lo enfoca desde abajo hacia arriba, enfatizando así el gesto amenazante, en tanto que de la víctima se realiza una toma inversa, sugiriendo la ocularización desde el monstruo y mostrando que aquella se halla inerme, a punto de caer en manos del agresor.

Sin embargo, no siempre estas angulaciones subrayadas de la cámara se articulan alternadamente, sino que por el contrario, se presentan de manera aislada. La secuencia de persecución y huida de Cesare por los techos en El gabinete del Dr. Caligari constituye uno de los contrapicados más emblemáticos dentro de este corpus (ver apéndice, fotograma 8).

En oposición a estas escenas en angulación hacia arriba que describen el vértigo de la fuga, se plantea en Nosferatu un encuadre en contrapicado similar, pero de cámara fija. Se trata de la llegada en barco del vampiro. Un plano de figura entera permite marcar el contraste entre el negro de la vestimenta y la palidez mortuoria del rostro y de las manos como garras; las cuerdas, roldanas y cadenas del velamen enmarcan a Nosferatu en esta toma de abajo hacia arriba de connotaciones siniestras (ver apéndice, fotograma 9).

Igualmente recurrentes en el cine de Weimar son los encuadres descentrados, que en El gabinete del Dr. Caligari se constituyen en verdadero estilema. Se privilegian en el film de Wiene los encuadres sobre ángulos con aristas, diseñando una geometría deliberadamente irregular y propiciando la organización asimétrica del espacio.

Pero acaso uno de los encuadres descentrados más estremecedores para el espectador se registre en Nosferatu, en un plano cuidadosamente compuesto. Me refiero a un fotograma que sitúa al monstruo en el instante en que se apresta a salir de un cajón que se halla en la cubierta del barco en el que viaja. Técnicamente constituye un peculiar sobreencuadre, ya que el vampiro, desplazado al ángulo izquierdo del plano, aparece enmarcado por los bordes de madera y la tapa semi-levantada del cajón. La toma, trabajada en un potente claroscuro, se resuelve en un primer plano del rostro desorbitado de Nosferatu, complementado por un plano detalle de una de sus manos de uñas larguísimas, muy poco humanas por cierto (ver apéndice, fotograma 10). 
La consideración de estos encuadres conduce a la pregunta por los espacios del monstruo. También en este punto es posible determinar algunas constantes. La figura monstruosa se desplaza, sea sigilosa, sea vertiginosamente, por techos, tejados, túneles, escaleras, lugares en ruinas o semiderruidos, bosques laberínticos. Asimismo, en planos estáticos, al monstruo se lo ubica en cavernas, castillos, espacios angulosos, e incluso -según se ha mencionado- en cajas o ataúdes, como sucede en el caso de Cesare en El gabinete del Dr. Caligari y de Nosferatu en la película homónima. Por otra parte, en varios de estos films como Homunculus, El Golem y Metrópolis- el laboratorio constituye uno de los espacios privilegiados, ya que en él se opera el "nacimiento" del humanoide, del híbrido -como lo definiría Massimo Izzi.

Repasando el corpus, se pueden distinguir construcciones espaciales más abstractas, -como en el paradigmático film de Robert Wiene que dio origen al término "caligarismo", en El Golem y en algunas secuencias de El gabinete de las figuras de cera-, y otras, sensiblemente menos estilizadas. El estudiante de Praga y ciertas escenas de Nosferatu por ejemplo, se sitúan en un clásico ambiente burgués, que contrasta con la trama fantástica del relato fílmico y subraya así -por contrapunto- lo ominoso. (Recordemos a propósito de esto, que Freud define a lo siniestro como ese cierto matiz de lo terrorífico que se produce cuando lo familiar se nos vuelve extraño.)

Se podría concluir entonces que en algunas películas, el diseño espacial está trabajado desde la redundancia, y en otras, desde el contrapunto. Los techos puntiagudos, las aristas marcadas, los ángulos cavernosos replican el aspecto deforme y la agresividad del monstruo, ${ }^{10}$ en tanto que las habitaciones de una casa burguesa no parecen adecuadas para albergar su presencia o recibir su irrupción.

Conviene aclarar que en algunos films conviven ambas modalidades de construcción espacial. Característico en este sentido es El gabinete de las figuras de cera, algunas de cuyas secuencias se acercan a la distorsión de una estética expresionista en la línea del caligarismo, en tanto que el relato marco y otros segmentos de la película se inclinan por el contraste realista.

Por último, en el tratamiento espacial no se puede soslayar la singularidad de Metrópolis, ciudad del futuro que alberga a la autómata. En su Historia del cine, Román Gubern, en una visión acertada, contrapone el "expresionismo pictórico" de El gabinete del Dr. Caligari, al "arquitectónico" de la película de Fritz Lang (Gubern, 1992, p. I, 240). También en Metrópolis hay túneles, cavernas y una suerte de extrañas

\footnotetext{
${ }^{10}$ Sánchez-Biosca utiliza incluso la expresión “espacio agresor” (Sánchez-Biosca, 1985, p. 65).
} 
catacumbas, donde la autómata arenga a la masa enardecida. Sin embargo estos espacios subterráneos conviven con una metrópolis "futurista", en uno de cuyos laboratorios cobró vida la autómata. ${ }^{11}$

Asociado con el monstruo y sus espacios, se construye asimismo un image system con distintos tipos de animales y alimañas, como ratas, arañas, gatos negros e incluso -en el caso de El estudiante de Praga- un perro que, sentado a la mesa de una taberna, sostiene una jarra de cerveza, mientras bebe de ella. Esta extravagancia aparece como incrustada en el ambiente burgués en el que se sitúa la acción de la película y acaso podría presagiar que algo anormal se está gestando en esa aparente calma cotidiana.

En nuestra exploración de estrategias discursivas fílmicas, debería considerarse asimismo la representación del monstruo mediante el recurso de sobreimpresión, procedimiento al que ya hemos hecho referencia en un apartado anterior. Dadas las limitaciones técnicas propias de la época, la sobreimpresión de fotogramas -recurrente en estos films- podría tomarse como equivalente de los efectos especiales del cine más cercano a nuestros días. En El Golem por ejemplo, mediante la sobreimpresión algo difuminada del torso y rostro de la criatura de arcilla sobre una de las callejuelas de la aldea llena de gente aterrorizada, se pretende no solo exhibir la superioridad física del monstruo y el dominio que este ejerce sobre la multitud, sino también hacer patente el espanto que el Golem provoca en el pueblo (ver apéndice, fotograma 1).

En Metrópolis por su parte, la sobreimpresión del rostro y los ojos de la Marie autómata intenta transmitir una similar idea de dominio del personaje monstruoso en relación con la masa de sus subyugados seguidores. Sin embargo en este caso, es diferente el vínculo que se establece con la multitud, ya que la autómata, lejos de generar pavor, despierta fascinación en esa masa humana, hasta el grado de producir una suerte de hipnosis colectiva.

Al igual que la de Metrópolis, otra sobreimpresión antológica en la historia del cine es la que introduce Murnau sobre el final de Nosferatu. Mediante este recurso, el espectador percibe cómo se va desvaneciendo la figura del vampiro, ubicado junto a las hojas de la ventana semiabierta, que dejan colar la luz incipiente de la madrugada, fatal para el monstruo (ver apéndice, fotograma 11).

\footnotetext{
${ }^{11}$ Acaso convenga recordar aquí la concepción arquitectónica propia de Lang y su sensibilidad para captar con la mirada, ya que se había formado como artista visual. Su padre, que era arquitecto, tenía la intención de que el hijo siguiera sus pasos, y de hecho, aunque más tarde el joven se rebelara y acabara abandonando el hogar paterno en busca de aventuras, libertad y lo que era su verdadera vocación, recibió desde temprana edad -ya a los quince años- una importante formación en arquitectura. El adolescente asistía a una Realschule, una especie de escuela secundaria técnica, y realizaba allí la orientación en arquitectura (Jensen, 1999, pp. 5-6). En el cine de Lang es posible vislumbrar esta formación temprana suya. Como la crítica ha hecho notar, el arquitecto que había en él se negaba a la distorsión de escenografías al estilo de Caligari por ejemplo (Jensen, 1999, p. 71).
} 
Finalmente, para completar este abordaje, restaría evaluar la elección de la puntuación dentro de nuestro corpus. En todos estos films, se aprecia el fundido a negro como modalidad de transición dominante, y en especial, un fundido subrayado, es decir francamente perceptible. Si bien es cierto que esta variante de puntuación, junto con el cierre en iris, responde a una convención de la época, en el corpus aquí propuesto parece exceder por momentos la mera función sintáctica. El fundido a negro no solo acompaña la oscuridad gótica de estas películas, sino que en ciertas escenas culminantes, se imprime sobre la criatura monstruosa. En el espectador, confrontado con la pantalla en negro, se prolonga e incluso se intensifica de esta manera el efecto perturbador que generara la escena que llegó a su fin con esa pausa. Aquello que podría decodificarse sencillamente como indicación de pasaje de una escena o secuencia a otra o como marca de elipsis, adquiere una carga ominosa al propiciar la evocación de las imágenes precedentes.

\section{A modo de conclusión}

Hasta aquí hemos tratado de sistematizar, recurriendo a un abordaje semiótico, algunas de las constantes de configuración y representación de lo monstruoso en películas paradigmáticas del llamado cine de Weimar.

Ya sobre el final de nuestro estudio, se amplifica el significado de aquellas palabras del recientemente desaparecido Umberto Eco que utilizamos como epígrafe: "Los monstruos no desaparecen con los mirabilia medievales." Simplemente adoptan formas nuevas, sugiere el autor italiano. Si continuamos reflexionando en pos de los postulados de Massimo Izzi, podría añadirse: cada época crea su monstruo o -en ominoso plural- sus monstruos. Frente a estas películas, tenemos la convicción de que la pantalla de Weimar supo, de manera magistral, dar forma a los suyos.

\section{Referencias Bibliográficas:}

AUMONT, Jacques. (1988). El rostro en el cine. Barcelona, Buenos Aires, México: Paidós. (Paidós Comunicación; Cine, 85)

CASETTI, Francesco. (1996). El film y su espectador. 2ª ed. Madrid: Cátedra. (Signo e imagen, 14)

ECO, Umberto. (2011). Historia de la fealdad. Barcelona: Bompiani / Random House Mondadori.

EISNER, Lotte. (1996). La pantalla demoníaca; las influencias de Max Reinhardt y el expresionismo. 2으. ed. Madrid: Cátedra. (Signo e imagen, 12) 
FUMAGALLI, Armando. (2004). I vestita nuovi del narratore: I'adattamento da letteratura a cinema. Milano: II Castoro.

GAY, Peter. (2011). La cultura de Weimar. Barcelona, Buenos Aires, México: Paidós. (Paidós Contextos, 201) GUBERN, Román. (1992). Historia del cine. Barcelona: Baber. 3 vol.

IZZI, Massimo. (1996). Diccionario ilustrado de los monstruos. Palma de Mallorca: José Olañeta Editor.

JENSEN, Paul. (1999). Sombras en el cine de Fritz Lang. Madrid: Ediciones JC Clementine. (Directores de cine)

KAYSER, Wolfgang. (1964). Lo grotesco; su configuración en pintura y literatura. Buenos Aires: Nova.

KRACAUER, Siegfried. (1995). De Caligari a Hitler; una historia psicológica del cine alemán. Barcelona, Buenos Aires, México: Paidós. (Paidós Comunicación; Cine, 73)

MELCHIOR-BONNET, Sabine. (2014). Historia del espejo. Buenos Aires: Edhasa / Club Burton.

PEDRAZA, Pilar. (2000). Fritz Lang, Metrópolis; estudio crítico. Barcelona, Buenos Aires, México: Paidós. (Paidós Películas, 9)

SÁNCHEZ-BIOSCA, Vicente. (1985). Del otro lado: la metáfora; modelos de representación en el cine de Weimar. Madrid: Hiperión. (Eutopías / Film)

TORRENGO, Giuliano. (2011). I viaggi nel tempo; una guida filosofica. Roma, Bari: Laterza. (Biblioteca di Cultura Moderna, 1212) 
Apéndice: Fotogramas.

Fotograma 1:

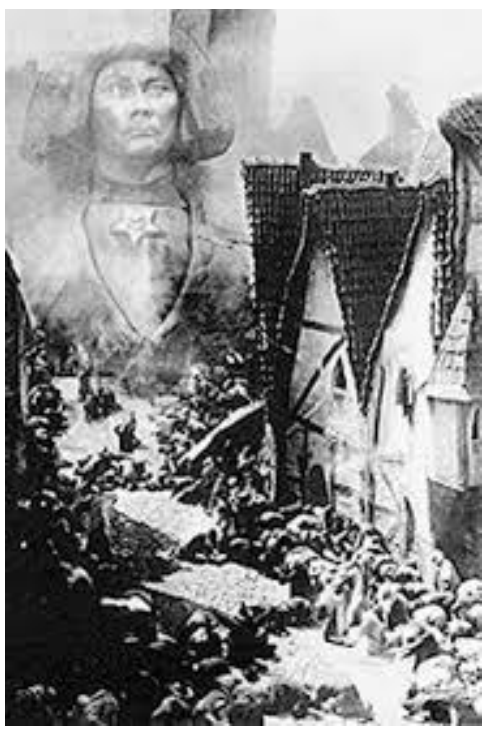

Fotograma 2:

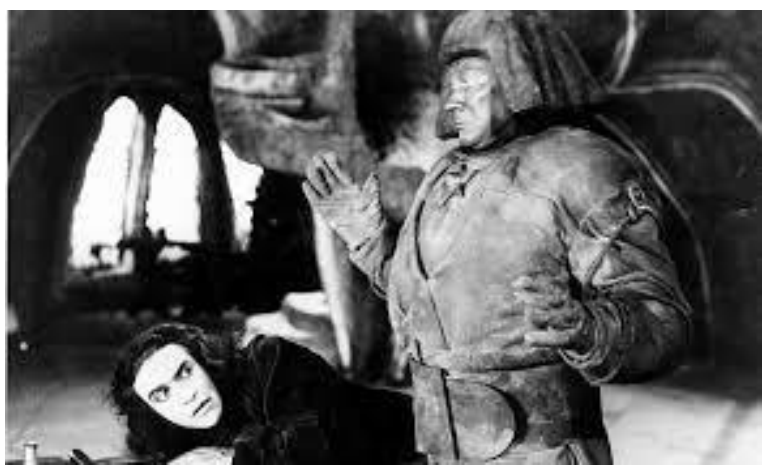

Fotograma 3:

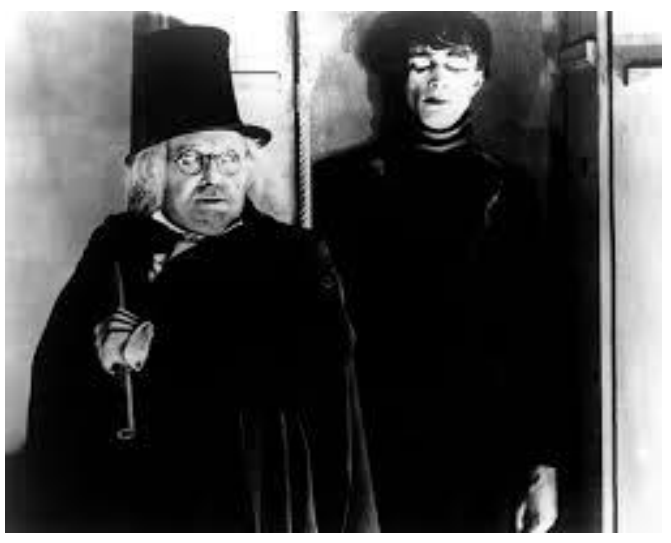




\section{Fotograma 4:}

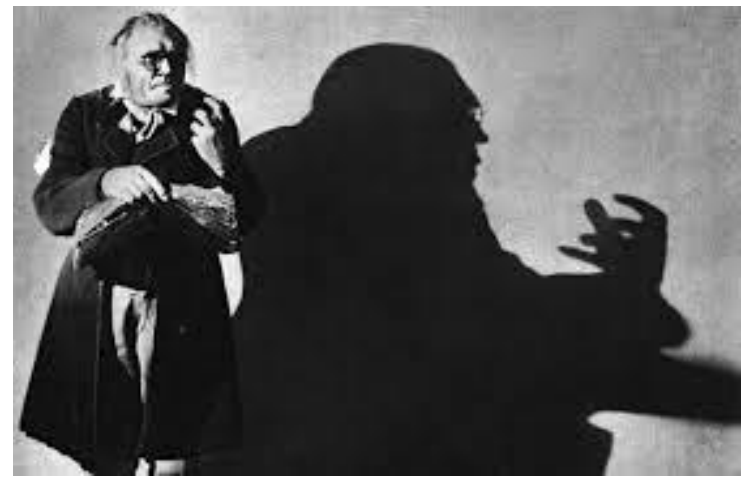

\section{Fotograma 5:}

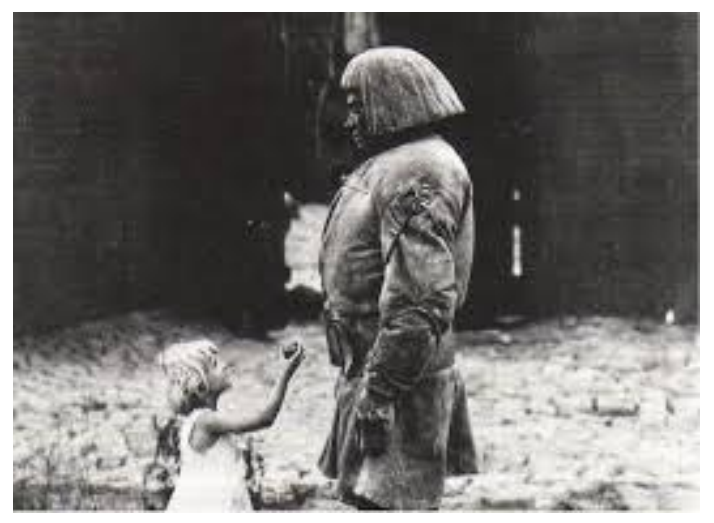

\section{Fotograma 6:}

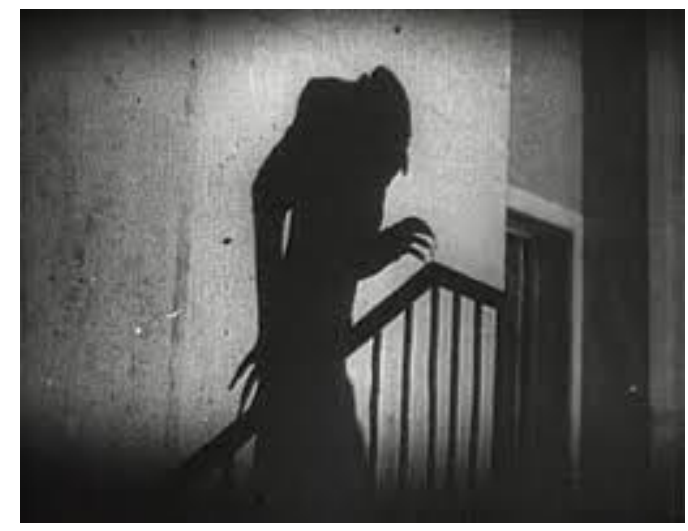




\section{Fotograma 7:}

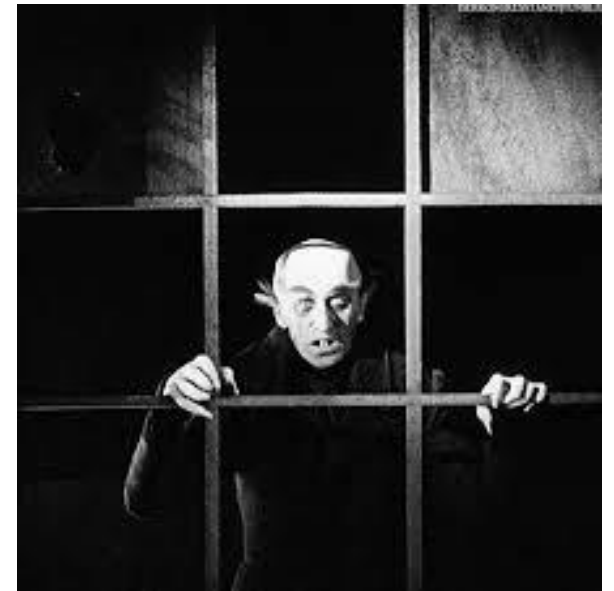

Fotograma 8:

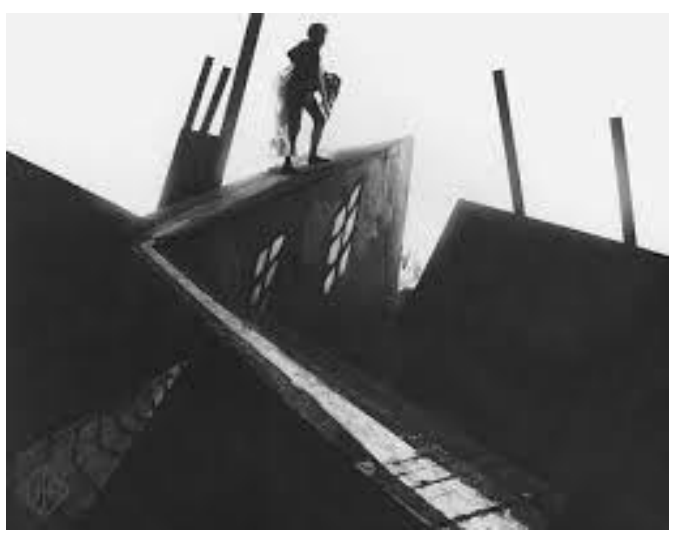

Fotograma 9:

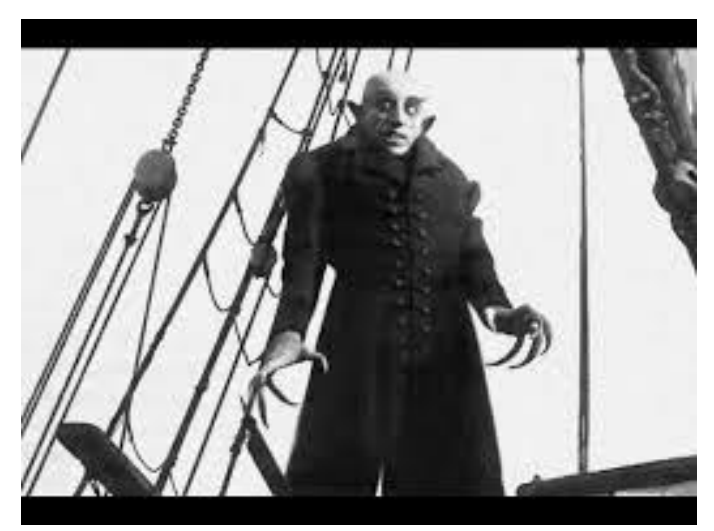


Fotograma 10:

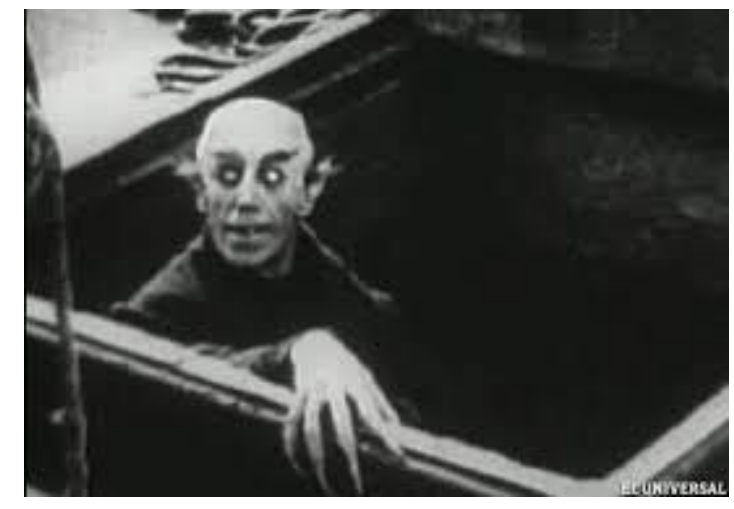

Fotograma 11:

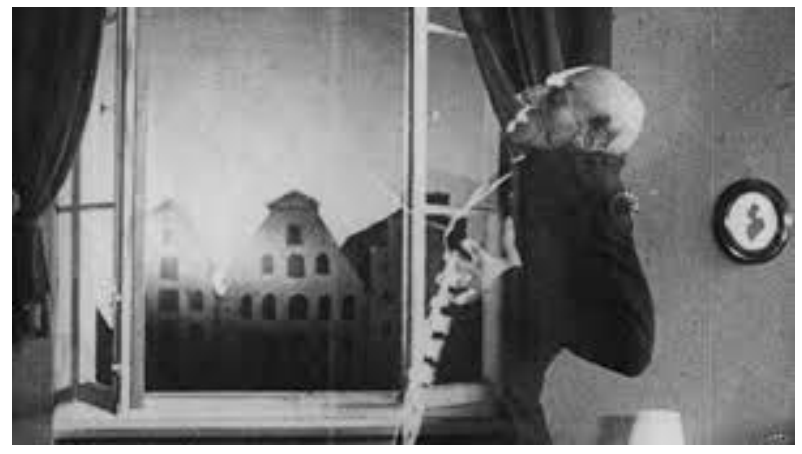

